\title{
Integrated Hydrological Modelling over Upstream Catchments of Himalayan Rivers and Assessment of Hydrological Events in Tehri Dam and Srinagar Catchments ${ }^{+}$
}

\author{
V. Sivashankari ${ }^{1, *}$, Amit Kumar Dubey ${ }^{2}$, K. Nivedita Priyadarshini ${ }^{1}$ and Sulochana Shekhar ${ }^{1}$ \\ 1 Department of Geography, School of Earth Sciences, Central University of Tamil Nadu, \\ Thiruvarur 610005, Tamil Nadu, India; nivi.darshini@yahoo.com (K.N.P.); sulochana@cutn.ac.in (S.S.) \\ 2 Space Applications Centre, Environment and Hydrology, Ahmedabad 380015, India; \\ a_dubey@sac.isro.gov.in \\ * Correspondence: shivaavettri@gmail.com; Tel.: +91-960-024-1370 \\ + Presented at the 2nd International Electronic Conference on Geosciences, 8-15 June 2019; Available online: \\ https://iecg2019.sciforum.net/.
}

Published: 5 June 2019

\begin{abstract}
Flash floods in the Himalayan Rivers result in hundreds of deaths causing a sudden hazard in a minimum period of time. These hydrological events of mostly happen due to cloudburst incidents in the Indian Himalayas, with an unexpected heavy overwhelming of precipitation in a short interval over a small region. These extreme hydrological events are assessed through the analytical hierarchy process for the upper stream catchments of Tehri Dam and Srinagar. The morphometry characteristics of these catchments are collaboratively integrated with the SAC (Space Application Centre) hydro simulated discharge and rainfall data to identify the flash-floodvulnerable hazard region over the surrounding catchment regions.
\end{abstract}

Keywords: flash floods; cloudburst; hydrological events; Analytical Hierarchy Process

\section{Introduction}

The eventuality of natural disasters associated with water, particularly flash floods, is a common phenomenon in the hilly part of the Indian Himalayas. The overwhelming of water in these hilly mountains is greater than the usual level, with some specific reasons of cloudburst in the catchment zone, and vigorous and lengthened rainfall causing the obstruction of river channels which induce the sudden breakage of artificial/natural lakes [1]. The cloudburst incidents are associated with the unusual steep slopes and bad inclines of the Himalayan orography, making the ultimate platform for flash flood activities. Even though advanced techniques have arisen, the prediction of these catastrophic occurrences remains unpredictable one [2]. The morphometry characteristics of the catchments enact the hydrological processes, in addition to observed parameters of discharge and intense rainfall data over the flash-flood-liable zones. The morphometric estimation of the drainage network helps to learn the behavioral characteristics of the drainage network and their impact on the flood-prone areas [3,4]. Drainage basins are delineated with a digital elevation model, and stream number and stream orders are computed by Strahler theory in order to assess flash flood vulnerability [5]. To understand the catchment response to hydrological events, various floodderiving parameters in morphometry analysis including rainfall, slope, drainage density, land use, etc., are predominantly assessed for flood hazards. However, there is difficulty in getting spatial prediction data from various sources due to inappropriate handling. The research on GIS tools 
reveals that flow direction, flow accumulation, precipitation, and drainage are some parameters for flooding events. These parameters are weighted by priority based on Saaty's nine-point scale and analyzed with the model of analytical hierarchy Process (AHP) [6,7]. The paper concentrates on the mapping of flood-vulnerable areas which are highly correlated in the Indian Himalayan rivers where the flash floods and cloudburst are common incidents. The decision-making techniques are used to understand this complex issue via analytical hierarchy process. The main objectives of this paper are to identify flood-vulnerable areas by the following steps:

1. Analysis of morphometry parameters using shuttle radar topography mission (SRTM) DEM integrated with discharge and rainfall data from SAC hydro model.

2. Normalization of these parametric classified values via analytical hierarchy process by assigning priority weight to each parameter.

\section{Materials and Methods}

\subsection{Study Area}

The study area Figure 1 shows Tehri Dam catchment is in the deep of Garhwal hills of Uttrakhand, includes the rivers Bhagirathi and Bhilangana, and is at the extent of $30.3781^{\circ} \mathrm{N}$ latitude and $78.4804^{\circ} \mathrm{E}$ longitude. The Srinagar catchment is extended at the latitude of $30.2247^{\circ} \mathrm{N}$ and longitude of $78.7986^{\circ} \mathrm{E}$, and has a major tributary of the Ganga river basin flowing through it, named Alaknanda.

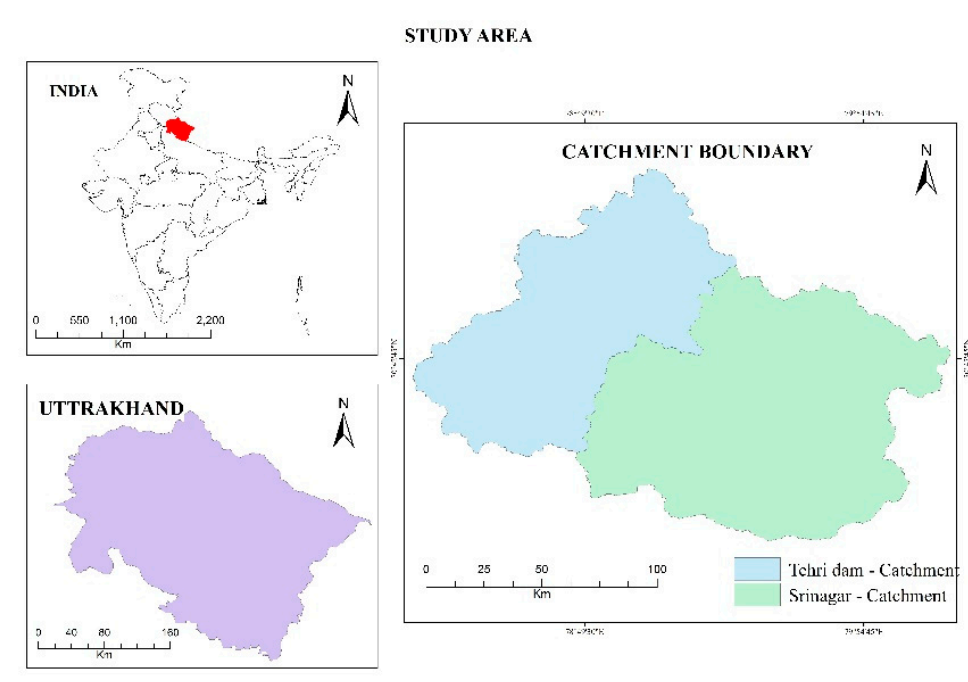

Figure 1. Location of the study area.

\subsection{Datasets}

The goals of this research paper were achieved by data gathered from different sources. Different GIS layers were created for the study area catchments. Shuttle radar topography mission (SRTM) DEM at the spatial resolution of $30 \mathrm{~m}$ was used for the determination of morphometric characteristics of the catchments, namely drainage density, slope, relief ratio and stream frequency, by delineating the catchment boundary regions. The SRTM DEM was used for the generation of the slope map and to produce hillshade regions along the catchment boundary. To study the catchment surface forms and their importance, these quantitative approaches of slope evaluation were used [8]. SAC hydro model, developed by Space Application Centre, Ahmedabad, provided daily average and accumulated discharge and rainfall data for India at a $5 \mathrm{~km}$ resolution. These datasets were gathered and incorporated in this study, and study area data were extracted using ArcGIS 10.5 software (Esri, Redlands, CA, USA). The National Resource Database (NRDB) was used to acquire a geological layer at the scale of 1:250,000. 


\subsection{Methodology}

The methodology in Figure 2 involved determining the causative parameters for flooding occurring in the study region catchments and finally, these causative criteria were put into the analytical hierarchy process to evaluate flood-susceptible zonation in the catchments.

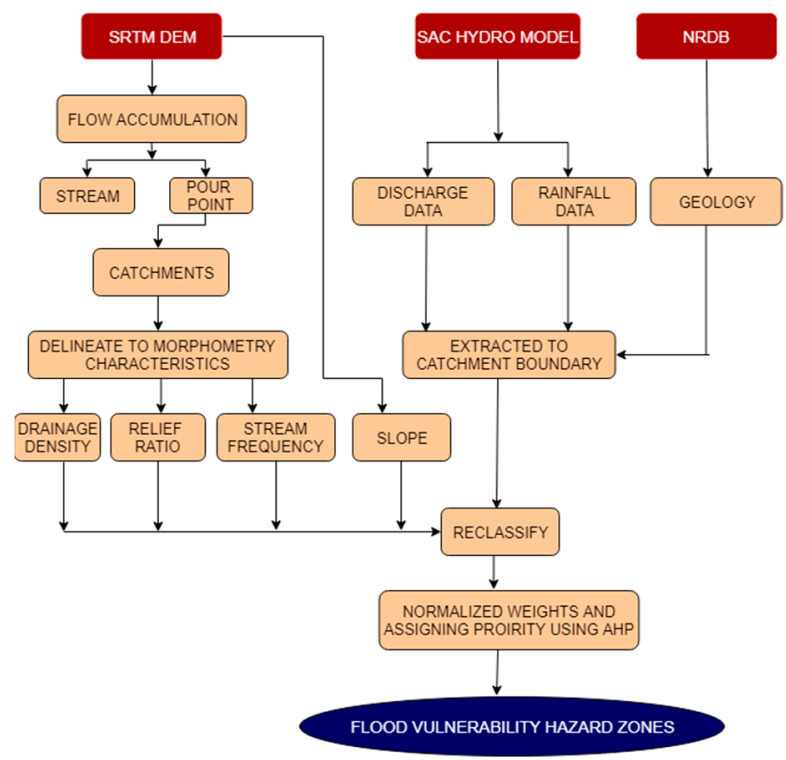

Figure 2. Flowchart for flood hazard zones.

\subsubsection{Development of Catchment Morphometry}

The two catchment morphometric parameters were inferred by using the linear, areal and relief characteristics. In this study, drainage density, relief ratio, and stream frequency are assessed to achieve the vulnerability assessment of two catchments [9]. Table 1 displays the calculations of catchment morphometry responses.

Table 1. Catchment morphometry parameters.

\begin{tabular}{|c|c|c|}
\hline Category & Parameter & Derivation Procedure \\
\hline Areal & $\begin{array}{l}\text { Drainage } \\
\text { Density }\end{array}$ & $\begin{array}{l}\mathrm{DD}=\Sigma \mathrm{L} / \mathrm{A} ; \text { where } \mathrm{DD}=\text { drainage density, } \Sigma \mathrm{L}=\text { sum of all stream lengths, and } \\
\mathrm{A}=\text { catchment area (Horton 1932) }\end{array}$ \\
\hline Areal & $\begin{array}{l}\text { Stream } \\
\text { Frequency }\end{array}$ & $\begin{array}{l}F_{s}=N_{u} / A ; F_{s}=\text { stream frequency, } N_{u}=\text { total length of stream, and } A=\text { catchment } \\
\text { area }(\text { Horton, 1945) }\end{array}$ \\
\hline Relief & Relief Ratio & $\begin{array}{l}\mathrm{Rh}=\mathrm{H} / \mathrm{L} ; \text { where } \mathrm{Rh}=\text { relief ratio, } \mathrm{H}=\text { horizontal distance along the longest } \\
\text { dimension in parallel to drainage line, and } \mathrm{L}=\text { length of the catchment } \\
\text { (Schumm, 1956) }\end{array}$ \\
\hline
\end{tabular}

\subsubsection{Analytical Hierarchy Process}

Analytical hierarchy process (AHP) provides a systematic approach for assessing and merging various factors to support the decision-making technique for various assessments, both qualitative and quantitative. This AHP technique helps to achieve the assessment of various factors and to solve the complex problems of overlapping and combined issues between multiple criteria factors. [10]. This framework was proposed and developed by Saaty's nine-point scale in 1980 for the decisionmaking process. The degree of consistency is solved by the consistency ratio (CR) and this CR should be less than or equal to 0.10 to imply that the pairwise matrix is acceptable. 


\section{Results and Discussion}

\subsection{Pair-Wise Comparison Matrix for Multi-Criteria and Its Consistency}

The pair-wise comparison matrix weighted the various parameters and found alternatives using absolute numbers of 1 to 9 in scale value of AHP. The weights were estimated by Microsoft Excel and priority index values were assigned to each parameter. Hence, the results contain relative weights of $\mathrm{C} 1=$ discharge, $\mathrm{C} 2=$ rainfall, $\mathrm{C} 3=$ slope, $\mathrm{C} 4=$ drainage density, $\mathrm{C} 5=$ geology, $\mathrm{C} 6=$ relief ratio, and $\mathrm{C} 7=$ stream frequency, as shown in Table 2. Therefore, the results were incorporated into the ArcGIS 10.5 software (Esri, Redlands, CA, USA) to identify the flood-vulnerable hazard zones over the catchment region [11].

Table 2. Pair-wise comparison matrix and its relative weight.

\begin{tabular}{cccccccccc}
\hline Parameters & C1 & C2 & C3 & C4 & C5 & C6 & C7 & Mean & Weight (\%) \\
\hline C1 & 0.53 & 0.72 & 0.64 & 0.42 & 0.48 & 0.36 & 0.33 & 0.50 & 50 \\
C2 & 0.07 & 0.09 & 0.16 & 0.17 & 0.14 & 0.18 & 0.17 & 0.14 & 14 \\
C3 & 0.07 & 0.05 & 0.08 & 0.17 & 0.14 & 0.18 & 0.21 & 0.13 & 13 \\
C4 & 0.11 & 0.05 & 0.04 & 0.08 & 0.10 & 0.09 & 0.08 & 0.08 & 8 \\
C5 & 0.08 & 0.05 & 0.04 & 0.06 & 0.07 & 0.09 & 0.08 & 0.07 & 7 \\
C6 & 0.09 & 0.03 & 0.03 & 0.06 & 0.05 & 0.06 & 0.08 & 0.06 & 6 \\
C7 & 0.07 & 0.02 & 0.02 & 0.04 & 0.03 & 0.03 & 0.04 & 0.04 & 4 \\
\hline
\end{tabular}

\subsection{Consistency Check}

The consistency of the pair-wise matrix was evaluated by the following index: $\mathrm{CR}=\mathrm{CI} / \mathrm{RI}$, where $\mathrm{CR}=$ consistency ratio, $\mathrm{CI}=$ consistency index , and $\mathrm{RI}=$ random index (the values were assigned as shown in Table 3).

Table 3. Random index value.

\begin{tabular}{cccccccccc}
\hline $\mathbf{n}$ & $\mathbf{1}$ & $\mathbf{2}$ & $\mathbf{3}$ & $\mathbf{4}$ & $\mathbf{5}$ & $\mathbf{6}$ & $\mathbf{7}$ & $\mathbf{8}$ & $\mathbf{9}$ \\
\hline $\mathrm{RI}$ & 0.00 & 0.00 & 0.58 & 0.90 & 1.12 & 1.24 & 1.32 & 1.41 & 1.45 \\
\hline
\end{tabular}

AHP theory indicates that the thumb-rule set of consistency ratio (CR) must be less than or equal to 0.1 . For this, foremost the consistency index is to be calculated using the following equation:

$$
C I=(\lambda \max -n) /(n-1) .
$$

From Table 1, $\lambda \max =7.36, \mathrm{n}=7$ (No. of parameters we used), then, $\mathrm{CI}=(7.36-7) /(7-1)=0.061$ which is less than 0.1 . Since CR's value is lower than the threshold (0.1) the weights' consistency is affirmed.

For every parameter, the ranges were classified and the index value was assigned based on the vulnerability characteristics as shown in Table 4. Every layer was reclassified with their range value and their index value was multiplied by their range value, then layers were again reclassified with the index value as shown in map of Figures 3 and 4. Once the weight in each factor was determined, the multi-criteria analysis was performed to produce a flood-vulnerable area by using the GIS approach. To compute the vulnerable area, a weight linear combination was applied as shown in the following equation: $Z=(50 \times$ discharge $)+(14 \times$ rainfall $)+(13 \times$ slope $)+(8 \times$ drainage density $)+(7 \times$ geology $)+(6 \times$ relief ratio $)+(4 \times$ stream frequency $)$. 
Table 4. Multi-criteria decision analysis for Tehri Dam and Srinagar catchment.

\begin{tabular}{|c|c|c|c|c|c|}
\hline \multirow{2}{*}{ Factor } & \multicolumn{2}{|c|}{ Tehri Dam Catchment } & \multicolumn{2}{|c|}{ Srinagar Catchment } & \multirow{2}{*}{ Weight } \\
\hline & Criteria & Index & Criteria & Index & \\
\hline \multirow{5}{*}{$\begin{array}{l}\text { Discharge } \\
\left(\mathrm{m}^{3} / \mathrm{s}\right)\end{array}$} & $0.01-50$ & 0.05 & $0.25-50$ & 0.05 & \multirow{5}{*}{$50 \%$} \\
\hline & 50-100 & 0.09 & 50-100 & 0.10 & \\
\hline & $100-500$ & 0.16 & $100-500$ & 0.13 & \\
\hline & 500-1000 & 0.26 & 500-1000 & 0.28 & \\
\hline & 1000-1749.02 & 0.45 & $1000-1736.81$ & 0.44 & \\
\hline \multirow{5}{*}{$\begin{array}{l}\text { Rainfall } \\
\text { (mm/day) }\end{array}$} & $62-189$ & 0.04 & $140.3-275.15$ & 0.05 & \multirow{5}{*}{$14 \%$} \\
\hline & $189-316$ & 0.09 & $275.15-410$ & 0.11 & \\
\hline & $316-443$ & 0.15 & $410-544.85$ & 0.16 & \\
\hline & $443-570$ & 0.31 & $544.85-679.7$ & 0.29 & \\
\hline & $570-697$ & 0.40 & $679.7-814.5$ & 0.40 & \\
\hline \multirow{5}{*}{ Slope $(\%)$} & $0-2$ & 0.43 & $0-2$ & 0.45 & \multirow{5}{*}{$13 \%$} \\
\hline & $2-7$ & 0.28 & $2-7$ & 0.27 & \\
\hline & $7-10$ & 0.15 & $7-10$ & 0.15 & \\
\hline & $10-15$ & 0.09 & $10-15$ & 0.09 & \\
\hline & $15-81.76$ & 0.05 & $15-87.56$ & 0.05 & \\
\hline \multirow{5}{*}{$\begin{array}{l}\text { Drainage } \\
\text { Density }\end{array}$} & $0.36-0.39$ & 0.05 & $0.34-0.38$ & 0.05 & \multirow{5}{*}{$8 \%$} \\
\hline & $0.39-0.41$ & 0.10 & $0.38-0.43$ & 0.12 & \\
\hline & $0.41-0.43$ & 0.18 & $0.43-0.47$ & 0.15 & \\
\hline & $0.43-0.45$ & 0.24 & $0.47-0.52$ & 0.26 & \\
\hline & $0.45-0.48$ & 0.43 & $0.52-0.56$ & 0.42 & \\
\hline \multirow{3}{*}{ Geology } & Sandy Loam & 0.66 & Sandy & 0.66 & \multirow{3}{*}{$7 \%$} \\
\hline & Sandy & 0.22 & Sandy Loam & 0.22 & \\
\hline & Snow/other & 0.12 & Snow/other & 0.12 & \\
\hline \multirow{5}{*}{$\begin{array}{l}\text { Relief } \\
\text { Ratio }\end{array}$} & $0.05-0.12$ & 0.43 & $0.04-0.09$ & 0.43 & \multirow{5}{*}{$6 \%$} \\
\hline & $0.12-0.18$ & 0.29 & $0.09-0.13$ & 0.28 & \\
\hline & $0.18-0.24$ & 0.15 & $0.13-0.17$ & 0.16 & \\
\hline & $0.24-0.30$ & 0.08 & $0.17-0.21$ & 0.08 & \\
\hline & $0.30-0.36$ & 0.05 & $0.21-0.26$ & 0.05 & \\
\hline \multirow{5}{*}{$\begin{array}{l}\text { Stream } \\
\text { Frequency }\end{array}$} & $0.18-0.20$ & 0.05 & $0.16-0.19$ & 0.05 & \multirow{5}{*}{$4 \%$} \\
\hline & $0.20-0.22$ & 0.10 & $0.19-0.22$ & 0.10 & \\
\hline & $0.22-0.24$ & 0.19 & $0.22-0.25$ & 0.19 & \\
\hline & $0.24-0.25$ & 0.26 & $0.25-0.27$ & 0.25 & \\
\hline & $0.25-0.27$ & 0.41 & $0.27-0.30$ & 0.40 & \\
\hline
\end{tabular}
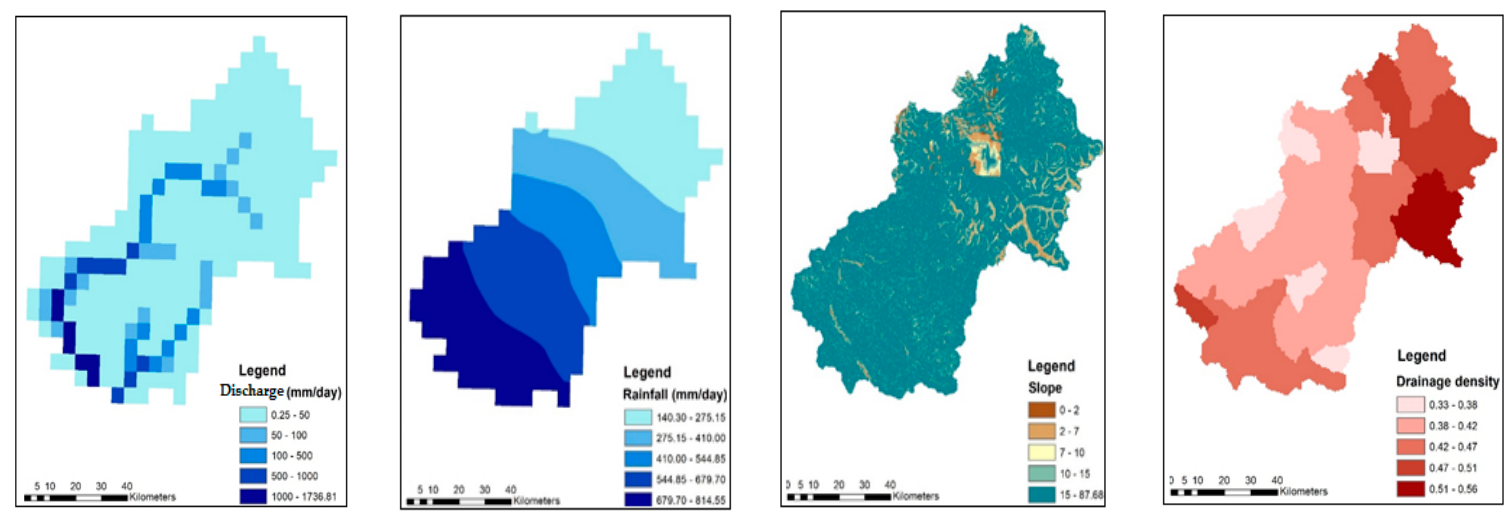

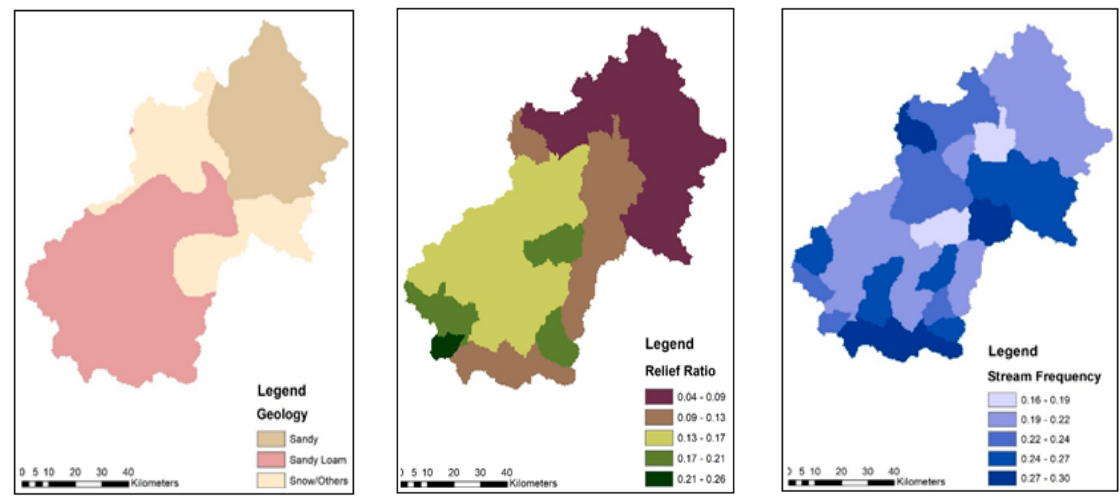

Figure 3. Multi-criteria parameter maps of Tehri Dam catchment.
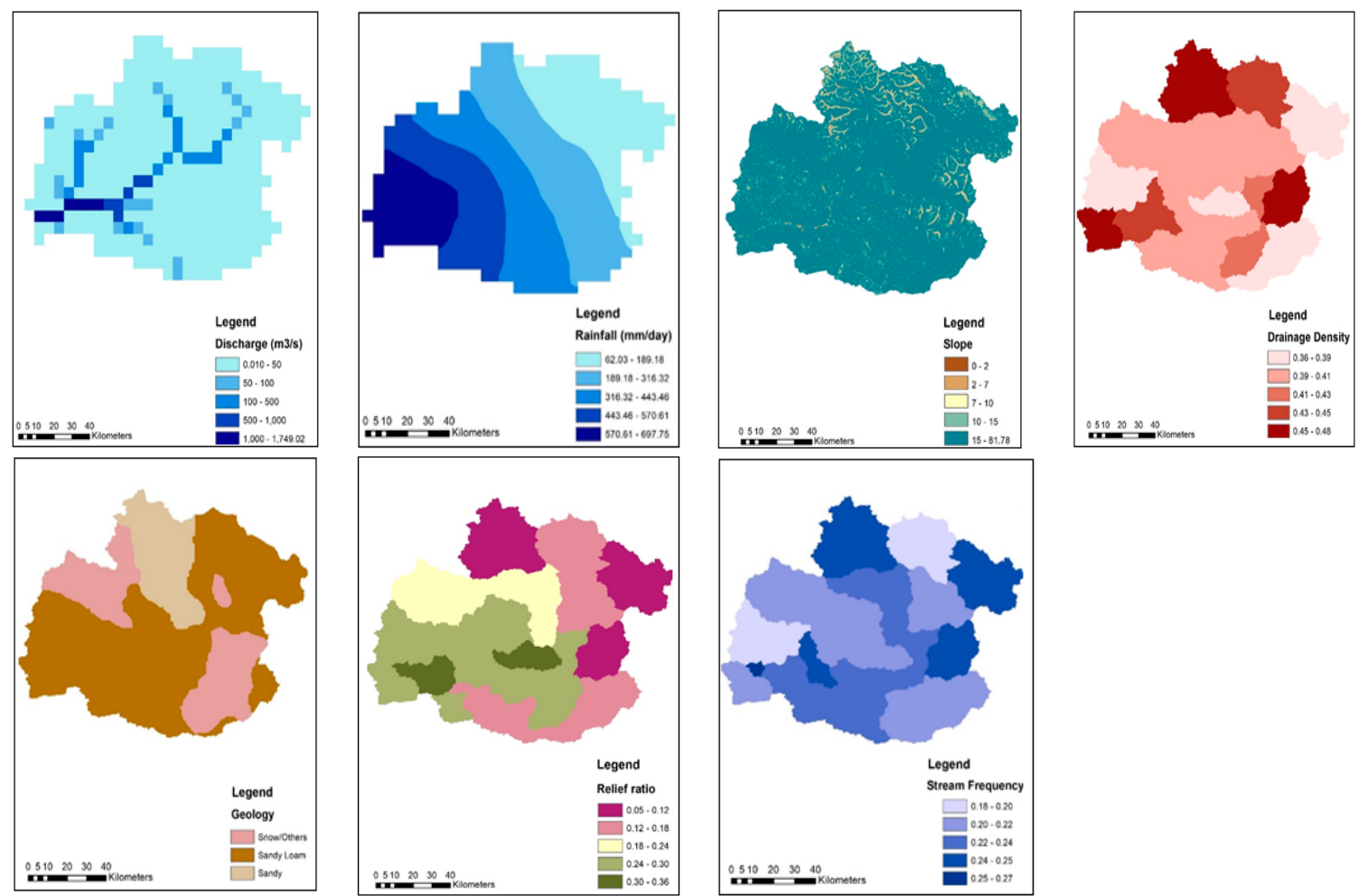

Figure 4. Multi-criteria parameter maps of Srinagar catchment.

The final vulnerability map output has been represented in Figure 5 with a graduated scale of a color map indicating the flood vulnerability. The vulnerability of flood areas was categorized into five criteria, namely "very high vulnerability", "high vulnerability", "moderate vulnerability", "low vulnerability", and "very low vulnerability". 

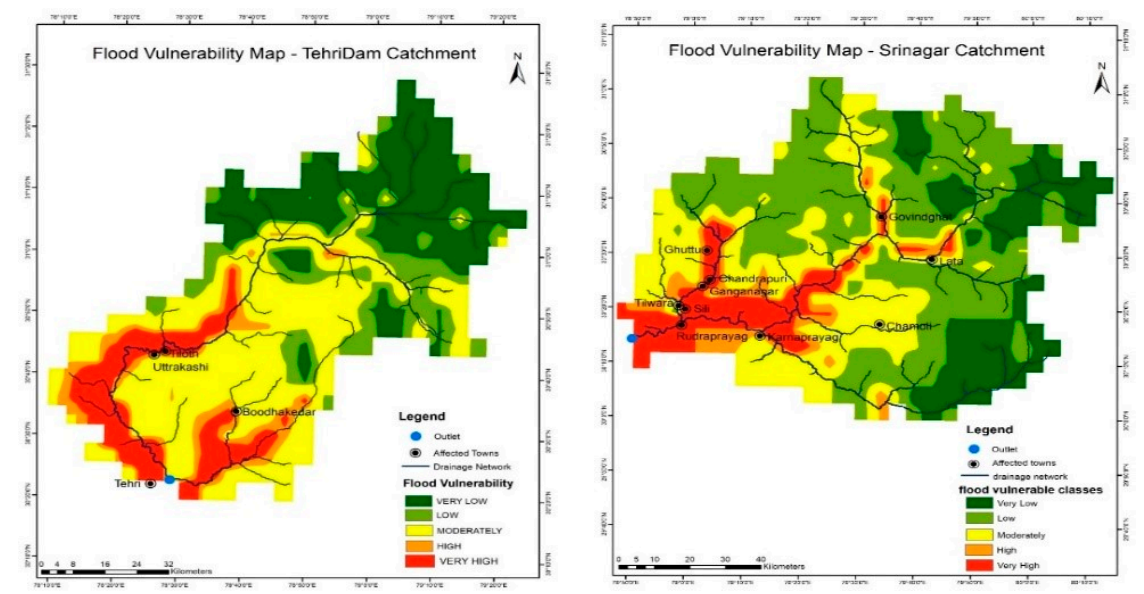

Figure 5. Flood vulnerability hazard zone map.

\subsection{Flood Hazard Area Estimation}

The above flood vulnerability hazard map (Figure 5) shows the range of vulnerable areas, with areas which are very highly prone to flash floods indicated as red zones. Generally, it is clearly seen that very high to highly prone areas are very close to the river Bhagirathi and the river Bhilanganga. The sudden flash flood causes a dramatic increase in river water level and creates a hazard to the livelihood of people in proximity to the river. The vulnerability area is calculated and shown in Table 5.

Table 5. Area calculation for the study area catchments.

\begin{tabular}{|c|c|c|c|c|}
\hline \multirow[b]{2}{*}{ Vulnerable Class } & \multicolumn{2}{|c|}{ Tehri Dam Catchment } & \multicolumn{2}{|c|}{ Srinagar Catchment } \\
\hline & $\begin{array}{c}\text { Area }\left(\mathrm{km}^{2}\right) \\
\text { Total Area }=7294.78 \mathrm{~km}\end{array}$ & Area (\%) & $\begin{array}{c}\text { Area }\left(\mathrm{km}^{2}\right) \\
\text { Total Area }=10,554 \mathrm{~km} \\
\end{array}$ & Area $(\%)$ \\
\hline Very Low & 2000.24 & $30 \%$ & 1775.52 & $18 \%$ \\
\hline Low & 800.1 & $12 \%$ & 3875.47 & $40 \%$ \\
\hline Moderate & 2775.34 & $41 \%$ & 2450.30 & $25 \%$ \\
\hline High & 425.05 & $6 \%$ & 525.06 & $5 \%$ \\
\hline Very High & 750.09 & $11 \%$ & 1050.13 & $11 \%$ \\
\hline
\end{tabular}

\section{Conclusions}

The assessment of flash flood hazard zone maps is necessary for identifying very highly prone areas where extreme weather events often happen. The final priority assessment map shows a clearcut decision on where flash floods can make a sudden and strong impact. The systematic approach of AHP helps to determine various criteria analyses, made at one time to produce the output results. In addition, the consistency ratio of the pair-wise comparison matrix is 0.06 which is acceptable at the thumb-rule set. Although the very highly prone areas show a relatively low area, the places where they are estimated are very close to the river line level. These catchments show very high vulnerability in the downstream region where the floods are accumulated and discharged. Future work will be carried out to determine the flash flood hazard zones in all Himalayan catchments.

Author Contributions: Conceptualization and Analysis, V.S. and K.N.P.; Writing-Original Draft Preparation, V.S. and K.N.P; Review and Editing, A.K.D. and S.S; Supervision, A.K.D. and S.S.

Conflicts of Interest: The authors declare no conflict of interest.

\section{References}

1. Sharma, D.D. Floods and Flash Floods in Himachal Pradesh: A Geographical Analysis; NIDM-National Institute of Disaster Management: New Delhi, India, 2006.

2. Dimri, A.P.; Chevuturi, A.; Niyogi, D.; Thayyen, R.J.; Ray, K.; Tripathi, S.N.; Pandey, A.K.; Mohanty, U.C. Cloudbursts in Indian Himalayas: A review. Earth-Sci. Rev. 2017, 168, 1-23. 
3. Diakakis, M. A method for flood hazard mapping based on basin morphometry: Application in two catchments in Greece. Nat. Hazards 2010, 56, 803-814.

4. Jesuleye, I.A.; Okeke, U.H.; Atijosan, A.O.; Badru, R.A.; Adewoyin, J. E.; Alaga, A.T. Morphometry assessment of Oba River basin and its implications for flood. J. Geogr. Environ. Earth Sci. Int. 2016, 8, 1-10.

5. Omran, A.; Schroeder, D.; El-Rayes, A.E.; Geriesh/Griesh, M.H. Flood hazard assessment in Wadi Dahab, Egypt based on basin morphometry using GIS techniques. In Proceedings of the Geoinformatics Forum Salzburg; Herbert Wichmann Verlag: Berlin/Offenbach, Germany, 2011; doi:10.13140/RG.2.1.2502.1520.

6. Matori, A.N.; Lawal, D.U.; Yusof, K.W.; Hashim, M.A.; Balogun, A.-L. Spatial analytic hierarchy process model for flood forecasting: An integrated approach. IOP Conf. Ser. Earth Environ. Sci. 2014, 20, 012029.

7. Zehra, S.; Afsar, S. Flood hazard mapping of lower indus basin using multi-criteria analysis. J. Geosci. Environ. Prot. 2016, 4, 54-62.

8. Samson, S.; Eludoyin, A.; Ogbole, J.; Alaga, A.; Oloko-Oba, M.; Okeke, U.; Popoola, O. Drainage Basin Morphometric Analysis for Flood Potential Mapping in Owu Using Geospatial Techniques. J. Geogr. Environ. Earth Sci. Int. 2016, 4, 1-8.

9. Oyatayo, K.T.; Iguisi, E.O.; Sawa, B.A.; Ndabula, C.; Jidauna, G.G.; Iorkua, S.A. Assessment of parametric flood vulnerability pattern of Makurdi Town, Benue State, Nigeria. Conflu. J. Environ. Stud. 2018, 12, 11-28.

10. Stefanidis, S.; Stathis, D. Assessment of flood hazard based on natural and anthropogenic factors using analytic hierarchy process (AHP). Nat. Hazards 2013, 68, 569-585.

11. Lawal, D.U.; Matori, A.N.; Hashim, A.M.; Yusof, K.W.; Chandio, I.A. Detecting flood-susceptible areas using GIS-based analytic hierarchy process. Int. Proc. Chem. Biol. Environ. Eng. 2012, 28, 1-5.

(C) 2019 by the authors. Licensee MDPI, Basel, Switzerland. This article is an open access article distributed under the terms and conditions of the Creative Commons Attribution (CC BY) license (http://creativecommons.org/licenses/by/4.0/). 